\title{
Formulation and Evaluation of Floating Tablets of Cefpodoxime Proxetil
}

\author{
L. Kukati ${ }^{*}$ K. Chittimalli, and N. B. Shaik \\ G. Pulla Reddy College of Pharmacy, Hyderabad, Andhra Pradesh, India-500028
}

Received 19 March 2013, accepted in final revised form 11 August 2014

\begin{abstract}
In present investigation, an attempt was made to develop gastro retentive tablets of cefpodoxime proxetil (CP) using locust bean gum as release retarded material. $\mathrm{CP}$ is an orally administered, extended spectrum, semi-synthetic antibiotic of cephalosporin class. CP has a short elimination half-life and also possesses high solubility, chemical, enzymatic stability and absorption profiles in acidic $\mathrm{pH}$ which makes $\mathrm{CP}$ suitable candidate for formulating it as gastro retentive dosage form for improved bioavailability. Sodium bicarbonate and citric acid were used as effervescent agents to get desired floating properties. The tablets prepared were evaluated and found to have acceptable physicochemical properties. The in vitro release data of optimized formulation was treated with mathematical equations and was concluded that drug release followed zero order kinetics with anomalous transport mechanism. Based on the results it can be concluded that floating tablets of cefpodoxime proxetil containing locust bean gum provides a better option for controlled release action and improved bioavailability.
\end{abstract}

Keywords: Cefpodoxime proxetil; Retardant material; Floating tablets.

(c) 2014 JSR Publications. ISSN: 2070-0237 (Print); 2070-0245 (Online). All rights reserved.

doi: http://dx.doi.org/10.3329/jsr.v6i3.18339 J. Sci. Res. 6 (3), 563-579 (2014)

\section{Introduction}

Oral drug delivery is the most preferred route among the different types of drug delivery systems for systemic effects due to ease of administration, patient compliance, economical and non invasive method. Sustained release dosage forms release the drug at a slow rate through oral route. Hence, it is highly desirable to develop sustained drug delivery systems, which releases the drug at predetermined rate to achieve optimal drug levels at the site of action. These systems have disadvantages like non suitability for the drugs having site specific absorption in the upper part of gastro intestinal tract (GIT), precipitation of drug, degradation of drug in distal part of GIT. This has resulted in the development of gastro retentive drug delivery systems (GRDDS) which overcomes the disadvantages associated with sustained release formulations.

Gastro retentive systems swells and retained in the stomach for a number of hours, while it continuously releases the drug at a controlled rate leading to higher

\footnotetext{
*Corresponding author: lathakukatil@gmail.com
} 
bioavailability, therapeutic efficacy, reduced time intervals for drug administration and thus improved patient compliance[1]. Hence these GRDDS are advantageous for the drugs absorbed mainly from the upper part of GIT having narrow absorption window and are unstable in the medium of distal intestinal regions [2]. They are even beneficial in the local therapy of the stomach.

In the present study, Cefpodoxime proxetil floating drug delivery system was prepared with locust bean gum as rate retarding material which contains galactomannans, plant reserve carbohydrates present in large quantities in the endosperm of the seeds of Ceratonia siliqua, leguminosae. They consist of a (1-4)-linked $\beta$-D-mannose backbone with (1-6)-linked side chains of $\alpha$ - D-galactose [3, 4] being thus neutral polymers [5].

\section{Materials \& Experimental Work}

\subsection{Materials}

Cefpodoxime proxetil gift samples are from Micro labs Pvt. Ltd., Bangalore. Citric acid anhydrous has been purchased from Universal Laboratories, Mumbai, whereas PVP K30 are obtained from Burgoyne Burbidges \& Co., Mumbai. Sodium bicarbonate, magnesium stearate are purchased from SD fine chemicals, Mumbai. All other chemicals, reagents and solvents used are of analytical grade. Locust bean gum purchased from Himedia laboratories Pvt. Ltd.

\subsection{Experimental work}

Cefpodoxime proxetil have good stability, solubility in acidic $\mathrm{pH}$. Tablets were prepared by wet granulation method using locust bean gum as retardant material.

\subsubsection{Preformulation studies}

Preformulation studies involve investigation of physical and chemical properties of a pure drug and with or without excipients. It is the first step in the rational development of dosage forms.

\subsubsection{Precompression parameters of powder blends and granules}

Required quantities of all the ingredients were subjected to grinding to a required degree of fineness then passed through sieve no. \#60. The granules were prepared by blending powder with PVP K 30 in Iso Propyl Alcohol (IPA) solution as granulating agent and the wet mass was screened using sieve no. \#44, then dried at $40{ }^{\circ} \mathrm{C}$ in hot air oven. The powder blend and dried granules are subjected for flow properties like angle of repose, bulk density, tapped density, Carr's index and Hausner's ratio [6]. 


\subsubsection{Angle of repose}

Angle of repose is the maximum angle possible between the surface pile of granules and horizontal plane. Fixed amount of blend was accurately taken and carefully poured through the funnel whose tip was secured at a height of $2.5 \mathrm{~cm}$ above the graph paper which is placed on a horizontal surface. The blend was poured until the apex of the conical pile just touches the tip of the funnel. Angle of repose is calculated by the following formula.

$$
\Theta=\tan ^{-1}(h / r)
$$

where, $\theta=$ angle of repose, $r=$ radius of the pile, $h=$ height of the pile.

\subsubsection{Bulk density}

Bulk density is defined as the ratio mass of an untapped powder divided by the bulk volume including the inter particulate void space. Apparent bulk density (BD) was determined by pouring the blend into a graduated cylinder. The bulk volume $(V)$ and weight of the powder $(M)$ was determined. The bulk density was calculated using the formula.

$$
\mathrm{BD}=M / V
$$

\subsubsection{Tapped density}

The tapped density attained after mechanically tapping of graduated measuring cylinder containing the powder sample by raising the cylinder or vessel and allowing it to drop, under its own mass. The measuring cylinder containing a known mass of blend was tapped for a fixed time (around 100). The minimum volume $\left(V_{\mathrm{t}}\right)$ occupied in the cylinder and the weight $(M)$ of the blend was measured. The tapped density (TD) was calculated using the formula,

$$
\mathrm{TD}=M /\left(V_{\mathrm{t}}\right)
$$

\subsubsection{Compressibility index}

Compressibility index is an indirect measure of bulk density, size and shape, surface area, moisture content and cohesiveness of materials. The correlation between compressibility index and powder flow properties is given in the formula,

$$
\mathrm{CI}(\%)=\text { Tapped density }(\mathrm{TD})-\text { Bulk density }(\mathrm{BD}) / \text { Tapped density }(\mathrm{TD}) \times 100
$$

\subsubsection{Hausner's ratio}

Is an indirect index of ease of powder flow and is measured by the ratio of tapped density to bulk density.

$$
\text { Hausner's ratio }=\text { Tapped density/ Bulk density }
$$




\subsubsection{Drug-excipient compatibility studies}

\subsubsection{Fourier transform infrared (FTIR)}

The spectrum analysis of pure drug and physical mixture of drug and different excipients which are used for preparation of tablets was studied by FTIR. FTIR spectra were recorded by preparing potassium bromide $(\mathrm{KBr})$ disks using a Shimadzu Corporation (Koyto, Japan). $\mathrm{KBr}$ disks were prepared by mixing few $\mathrm{mg}$ of sample with potassium bromide and compressed at 10 tons pressure. The resultant disc was mounted in a suitable holder in IR spectrophotometer and the spectrum was recorded from $4000 \mathrm{~cm}^{-1}$ to 500 $\mathrm{cm}^{-1}$.

\subsection{Formulation of cefpodoxime proxetil floating tablets}

\subsubsection{Dose calculation [7]}

Cefpodoxime is available in proxetil salt form. Dose is calculated based on its $t^{1 / 2}$ and $V \mathrm{~d}$.

$$
K^{0} r=\text { Rate in }=\text { Rate out }=K \text { e } \cdot C \mathrm{~d} \cdot V \mathrm{~d}
$$

where $K^{0} r$ is the zero-order rate constant for drug release (amount/time), $K e$ is the firstorder rate constant of overall drug elimination $\left(\mathrm{hr}^{-1}\right), \mathrm{Cd}$ is the desired drug level in the body (amount/volume), and $V \mathrm{~d}$ is the volume in which the drug is distributed.

$$
K \mathrm{e}=0.693 / t^{1 / 2}
$$

$t^{1 / 2}$ ( elimination half-life) of cefpodoxime proxetil is 2.4 hours then $K \mathrm{e}=0.693 / 2.4=$ $0.288 \mathrm{Hr}^{-1}$.

If $C \mathrm{~d}$ is $1.4 \mathrm{mg} / \mathrm{L}$, and $V \mathrm{~d}$ is $32.3 L$, then $K^{0} r=K$ e. $C \mathrm{~d} . V \mathrm{~d}=13.05 \mathrm{mg} / \mathrm{h}$.

$K^{0} r$ calculated was $13.05 \mathrm{mg} / \mathrm{h}$, so the drug release constant should also be equal to the elimination constant so as to maintain the steady-state condition.

Cefpodoxime is not completely absorbed if taken orally; only 50\% of the drug is absorbed in fasting conditions. The percent absorbed is improved if the drug is taken with food, to $\sim 75 \%$ of the dose administered.

$$
\begin{aligned}
& K^{0} r=13.05 * 125 / 100=16.32 \mathrm{mg} / \mathrm{h} \\
& D \mathrm{~L}=D \mathrm{i}-K^{0} r T \mathrm{p} \quad(\mathrm{DL}=\text { Loading dose; } \mathrm{Di}=\text { initial dose })
\end{aligned}
$$

Time to reach the peak drug level (Tp) is 2.5 hours.

$$
D \mathrm{~m}=K^{0} r T \mathrm{~d}
$$

Total dose $(\mathrm{Td})=$ Loading dose $(\mathrm{DL})+$ Maintenance Dose $(\mathrm{Dm})$

where $T \mathrm{~d}$ is the total time desired for sustained release from 1 dose (i.e., 12 hours).

Hence, total dose $=(100-16.32 * 2.5)+16.32 * 12=(100-40.8)+195.28=255.04$ Since $130 \mathrm{mg}$ of cefpodoxime proxetil is equivalent to $100 \mathrm{mg}$ of cefpodoxime. Thus

Total dose $=255.04 * 1.3=331.55 \mathrm{mg}$. Hence the quantity used was (nearly) 330 $\mathrm{mg} /$ tablet. 


\subsubsection{Preparation of tablets}

Tablets are prepared by wet granulation method using effervescent agent. All the ingredients locust bean gum, sodium bicarbonate, citric acid and drug were passed through the sieve no. \#60. Granules were prepared using 5\% PVP in IPA as binder solution and passed through sieve no. \#44. Granules were dried at $40^{\circ} \mathrm{C}$ for $2 \mathrm{hrs}$ and passed through sieve no. \#30. Granules were lubricated with magnesium stearate. Formulations were prepared as given in the Table 1 and compressed in to tablets on a 10 station rotary tablet machine using $11.9 \mathrm{~mm}$ punches.

Table 1. Formulation of cefpodoxime proxetil floating tablets.

\begin{tabular}{lcccccc}
\hline $\begin{array}{l}\text { Formulation } \\
\text { code }\end{array}$ & $\begin{array}{l}\text { Cefpodoxime } \\
\text { proxetil } \\
(\mathrm{mg})\end{array}$ & $\begin{array}{l}\text { Locust } \\
\text { bean gum } \\
(\mathrm{mg})\end{array}$ & $\begin{array}{l}\text { Sodium } \\
\text { bicarbonate } \\
(\mathrm{mg})\end{array}$ & $\begin{array}{l}\text { Citric } \\
\text { acid } \\
(\mathrm{mg})\end{array}$ & $\begin{array}{l}\text { Magnesium } \\
\text { stearate } \\
(\mathrm{mg})\end{array}$ & $\begin{array}{l}\text { PVP } \\
(\mathrm{mg})\end{array}$ \\
\hline F1 & 330 & 198 & 52.8 & - & 6 & 29.3 \\
F2 & 330 & 198 & 79.2 & - & 6 & 30.6 \\
F3 & 330 & 198 & 105.6 & - & 6.3 & 31.9 \\
F4 & 330 & 198 & 132 & - & 6.6 & 33.3 \\
F5 & 330 & 132 & 115.5 & - & 6 & 29.1 \\
F6 & 330 & 132 & 138.6 & - & 6 & 30.3 \\
F7 & 330 & 100 & 86 & - & 5 & 27.12 \\
F8 & 330 & 100 & 107.5 & - & 5.5 & 28.2 \\
F9 & 330 & 100 & 129 & - & 5.8 & 29.3 \\
F10 & 330 & 115.5 & 113.7 & - & 5.5 & 28.2 \\
F11 & 330 & 115.5 & 90 & 63 & 6 & 30.2 \\
F12 & 330 & 115.5 & 90 & 81 & 6 & 31.1 \\
F13 & 330 & 115.5 & 111.37 & 77.9 & 6.3 & 32 \\
\hline
\end{tabular}

\subsection{Evaluation of cefpodoxime proxetil floating tablets}

The prepared bilayer tablets are evaluated for varied parameters like weight variation, thickness, hardness, friability [6], drug content, content uniformity and in vitro dissolution studies [8].

\subsubsection{Tablet thickness}

The thickness in millimeters $(\mathrm{mm})$ was measured individually for 10 pre-weighed tablets by using vernier calipers. The average thickness and standard deviation were reported.

\subsubsection{Tablet hardness}


Tablet hardness was measured using monsanto hardness tester. The average crushing strength of the 5 tablets with known weight and thickness of each was reported.

\subsubsection{Friability test}

Ten tablets were accurately weighed and placed in the friability test apparatus (Roche friabilator), rotated at $25 \mathrm{rpm}$ for 4 minutes. The tablets were taken, dedusted and reweighed. The friability was calculated as the percentage weight loss using Eq. 11. Friability values below $1 \%$ are generally acceptable.

$$
\% \text { Friability }=\left(W_{1}-W_{2}\right) \times 100 / W_{1}
$$

where, $W_{1}=$ initial weight of the tablets, $W_{2}=$ final weight of the tablets.

\subsubsection{Weight Variation Test}

To study weight variation individual weights $\left(W_{\mathrm{I}}\right)$ of 20 tablets from each formulation were noted down using electronic balance. Their average weight $\left(W_{\mathrm{A}}\right)$, percentage weight variation were calculated using Eq. 12.

$\%$ Weight variation $=\left(W_{\mathrm{A}}-W_{\mathrm{I}}\right) \times 100 / W_{\mathrm{A}}$

\subsubsection{Drug content [9]}

Ten tablets were weighed and taken into a mortar and crushed into fine powder. An accurately weighed portion of the powder equivalent to $100 \mathrm{mg}$ of Cefpodoxime proxetil was transferred to a $100 \mathrm{ml}$ volumetric flask containing methanol. It was shaken by mechanical means for $1 \mathrm{hr}$. Then it was filtered through what man filter paper. From this resulted solution $1 \mathrm{ml}$ was taken, diluted to $10 \mathrm{ml}$ with $0.1 \mathrm{~N} \mathrm{HCl}$ and absorbance was measured against blank at $264.2 \mathrm{~nm}$ using UV-Spectrophotometer. The drug content of the floating tablets meets the requirements if the tablet amount lies within the range of $90 \%$ to $110 \%$.

\subsubsection{Buoyancy/floating test}

The tablet is introduced into a $100 \mathrm{ml}$ beaker containing $0.1 \mathrm{~N} \mathrm{HCl}$ and the time gap between the introduction and time for tablet to emerge onto surface of medium is called "floating lag time". The total duration of time by which dosage form remain buoyant is called "Total floating time (TFT)".

\subsubsection{In vitro dissolution studies [9]}

The tablet was placed in a dissolution test apparatus USP II, containing $900 \mathrm{ml}$ of $0.1 \mathrm{~N}$ $\mathrm{HCl}$ at speed of $50 \mathrm{rpm} .5 \mathrm{ml}$ of aliquot was withdrawn for every $1 \mathrm{hr}$ up to $12 \mathrm{hrs}$ and 
replaced with $5 \mathrm{ml}$ of fresh dissolution medium. Each sample was analyzed at $264.2 \mathrm{~nm}$ using double beam UV spectrophotometer against reagent blank.

\subsubsection{Determination of gastric retention period by $x$-ray imaging studies}

Evaluation of gastric retention of Cefpodoxime proxetil sintered floating tablet was performed on rabbit by the use of radio opaque marker barium sulfate. X-Ray imaging studies are non-invasive method, provides identification or monitoring of total GI residence time without affecting normal gastro intestinal motility.

Dose translation was based on Body Surface Area (BSA). The animal dose should not be extrapolated to a Human Equivalent Dose (HED) by a simple conversion based on body weight, as reported.

The rabbit dose was calculated according to the following equation:

Animal dose $(\mathrm{mg} / \mathrm{kg})=$ Human equivalent dose $\times$ Human $\mathrm{Km}$ value $/$ Animal $\mathrm{Km}$ value

Conversion: dose in $\mathrm{mg} / \mathrm{kg}=$ dose in $\mathrm{mg} / \mathrm{m}^{2} \times K \mathrm{~m}$ value.

Human (human adult of weight $60 \mathrm{~kg}$ ) $\mathrm{Km}$ value is 37, animal (rabbit weighing $1.8 \mathrm{~kg}$ ) $K \mathrm{~m}$ value is12.

Values based on data from FDA Draft Guidelines.

Animal dose $(\mathrm{mg} / \mathrm{kg})=5.5 \times 37 / 12=5.5 \times 3.08=16.94 \mathrm{mg} / \mathrm{kg}$.

Rabbit under study was weighing $1.9 \mathrm{~kg}$. So dose $=16.94 \times 1.9=32.1 \mathrm{mg}$.

Hence the dose for in vivo studies taken was $32.1 \mathrm{mg}$. $25 \%$ of drug was replaced with barium sulfate i.e., so $8.025 \mathrm{mg}$ per each tablet. The formulas for in vivo gastro retentive tablets are given in Table 2 .

Table 2. Formula for animal dose.

\begin{tabular}{ccc}
\hline Sl. & Ingredients & Quantity taken $(\mathrm{mg})$ \\
\hline 1 & Cefpodoxime proxetil & 24 \\
2 & Barium sulfate & 8 \\
3 & Locust bean gum & 7.2 \\
4 & Camphor & 4 \\
5 & Magnesium stearate & 0.5 \\
6 & PVP K 30 & 2.18 \\
\hline
\end{tabular}

Healthy rabbit of $2.00 .2 \mathrm{~kg}$ was fasted over night and on the next day morning, selected tablet (F13) which was adjusted to rabbit dose and containing barium sulfate in place of cefpodoxime proxetil was administered through plastic tubing followed by flushing of 25-30 $\mathrm{ml}$ of water. During the entire study, the rabbits had free access to water only. At different time intervals of $0,1,2,4,6$ and 8 hours, rabbit G.I.T. was X-Ray 
photographed in supine position and observed for the nature and position of the cefpodoxime proxetil floating tablet.

\subsubsection{Accelerated stability studies}

Optimized formulation F13 was subjected to stability studies at $40{ }^{\circ} \mathrm{C} \pm 2{ }^{\circ} \mathrm{C} / 75 \% \pm 5 \%$ $\mathrm{RH}$ and room temperature analyzed for its physical characteristics, drug content and dissolution every month for period of one month.

\section{Results and Discussion}

\subsection{Preformulation studies}

3.1.1. Drug-excipients compatibility study by FTIR

Cefpodoxime proxetil compatibility with excipient was studied by FTIR.

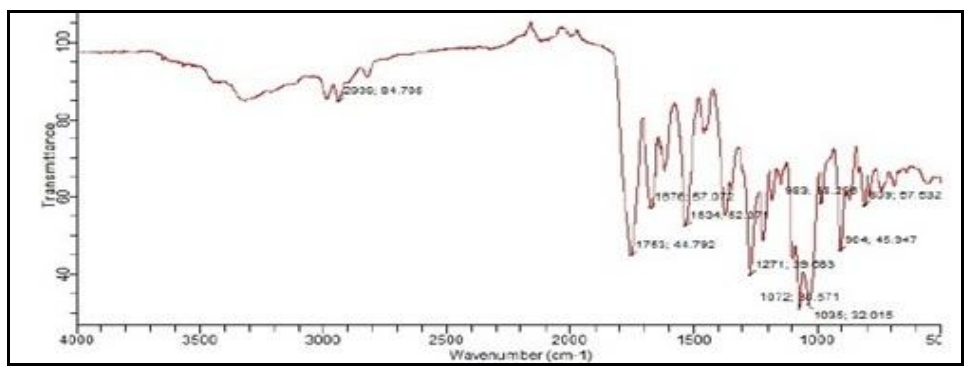

(a)

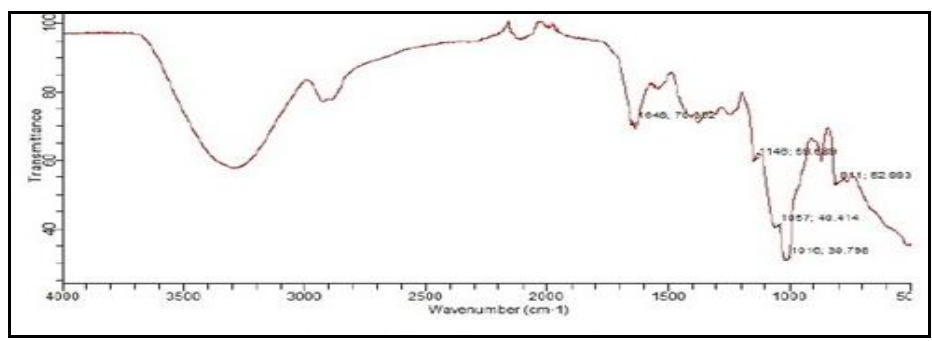

(b) 


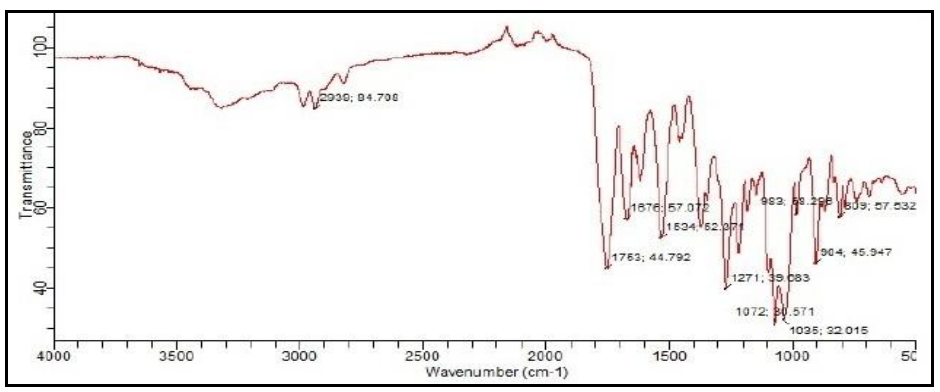

(c)

Fig. 1. FTIR spectra of (a) Cefpodoxime proxetil (b) locust bean gum and (c) physical mixture of cefpodoxime and locust bean gum.

Table 3. Interpretation of cefpodoxime proxetil FTIR scan.

\begin{tabular}{rrll}
\hline Sl. & $\begin{array}{c}\text { Region in } \\
\mathrm{cm}^{-1}\end{array}$ & Type of vibration & $\begin{array}{l}\text { Functional group } \\
\text { present }\end{array}$ \\
\hline 1 & $\begin{array}{r}3396.41, \\
3230.54\end{array}$ & N-H stretching & Primary amine \\
2 & 1676 & N-H bending & $\begin{array}{l}\text { Aromatic primary } \\
\text { Amine }\end{array}$ \\
3 & 1274 & C-N & Amine \\
4 & 3066.61 & $\begin{array}{l}\text { Aromatic C-H } \\
\text { stretch }\end{array}$ & Aromatic \\
5 & 1638 & C=N & -- \\
6 & 809 & C-S-C stretching & -- \\
7 & 1753 & C=O & Lactam \\
\hline
\end{tabular}

From the above IR graphs (Fig. 1) the peaks representing the pure drug were similar in all the graphs suggesting that there is no interaction and the pure drug is unaltered when mixed with Locust bean gum.

\subsubsection{Evaluation of flow properties}

Table 4. Pre compression parameters of the powder blends.

\begin{tabular}{lccc}
\hline Ingredients & $\begin{array}{c}\text { Angle of } \\
\text { repose }(\Theta)\end{array}$ & $\begin{array}{c}\text { Hausner's } \\
\text { ratio* }^{*}\end{array}$ & $\begin{array}{c}\text { Carr's } \\
\text { index }(\%)\end{array}$ \\
\hline $\begin{array}{l}\text { Drug } \\
\begin{array}{l}\text { Drug+ locust } \\
\text { bean gum }\end{array}\end{array}$ & $53.3 \pm 0.54$ & $1.40 \pm 0.09$ & $29.67 \pm 0.2$ \\
$\begin{array}{l}\text { Drug + LG + } \\
\text { sodium } \\
\text { bicarbonate }\end{array}$ & $47 \pm 0.65$ & $1.41 \pm 0.08$ & $23.82 \pm 0.73$ \\
$\begin{array}{l}\text { Drug + LG + } \\
\text { camphor }\end{array}$ & $50 \pm 0.49$ & $1.46 \pm 0.02$ & $24.1 \pm 0.17$ \\
\hline \multicolumn{2}{l}{ Values are expressed as mean $\pm \mathrm{SD}, * n=3}$. & \\
\hline
\end{tabular}


It was found that the drug and the other powder blends do not possess the required flow characteristics for direct compression as the values of angle of repose, hausner's ratio, carr's compressibility index were found to be within flow property limits i.e. 50, 1.46 and 24.1 respectively shown in Table 4. Hence tablets were prepared by wet granulation method.

Table 5. Precompression parameters of the granules

\begin{tabular}{cccccc}
\hline $\begin{array}{c}\text { Formulation } \\
\text { code }\end{array}$ & $\begin{array}{c}\text { Angle of } \\
\text { repose }(\theta)^{*}\end{array}$ & $\begin{array}{c}\text { Bulk } \\
\text { density } \\
\left(\mathrm{gm} / \mathrm{cm}^{3}\right)^{*}\end{array}$ & $\begin{array}{c}\text { Tapped } \\
\text { density } \\
\left(\mathrm{gm} / \mathrm{cm}^{3}\right)^{*}\end{array}$ & $\begin{array}{c}\text { Hausner's } \\
\text { ratio }\end{array}$ & $\begin{array}{c}\text { Carr's } \\
\text { index }(\%)^{*}\end{array}$ \\
\hline F1 & $24.20 \pm 1.0$ & $0.33 \pm 0.01$ & $0.416 \pm 0.00$ & $1.25 \pm 0.019$ & $20.10 \pm 1.52$ \\
F2 & $26.62 \pm 0.98$ & $0.316 \pm 0.00$ & $0.365 \pm 0.01$ & $1.19 \pm 0.00$ & $16.32 \pm 0.11$ \\
F3 & $21.36 \pm 0.82$ & $0.317 \pm 0.01$ & $0.372 \pm 0.00$ & $1.170 \pm 0.013$ & $13.58 \pm 0.92$ \\
F4 & $27.89 \pm 0.80$ & $0.348 \pm 0.01$ & $0.416 \pm 0.01$ & $1.19 \pm 0.022$ & $16.27 \pm 0.039$ \\
F5 & $19.08 \pm 0.72$ & $0.345 \pm 0.01$ & $0.442 \pm 0.01$ & $1.22 \pm 0.001$ & $18.24 \pm 0.16$ \\
F6 & $21.62 \pm 0.53$ & $0.342 \pm 0.012$ & $0.380 \pm 0.00$ & $1.23 \pm 0.021$ & $21.89 \pm 0.56$ \\
F7 & $26.89 \pm 0.92$ & $0.319 \pm 0.024$ & $0.377 \pm 0.00$ & $1.201 \pm 0.019$ & $16.62 \pm 0.32$ \\
F8 & $28.47 \pm 0.92$ & $0.334 \pm 0.01$ & $0.4527 \pm 0.00$ & $1.24 \pm 0.04$ & $19.88 \pm 0.33$ \\
F9 & $28.97 \pm 0.86$ & $0.3330 \pm 0.01$ & $0.410 \pm 0.01$ & $1.26 \pm 0.019$ & $20.24 \pm 1.49$ \\
F10 & $27.78 \pm 0.78$ & $0.362 \pm 0.01$ & $0.4712 \pm 0.01$ & $1.28 \pm 0.07$ & $20.82 \pm 0.07$ \\
F11 & $28.58 \pm 0.94$ & $0.334 \pm 0.01$ & $0.428 \pm 0.003$ & $1.30 \pm 0.09$ & $22.16 \pm 1.20$ \\
F12 & $24.62 \pm 0.90$ & $0.325 \pm 0.00$ & $0.399 \pm 0.00$ & $1.21 \pm 0.02$ & $17.20 \pm 0.12$ \\
F13 & $23.26 \pm 0.69$ & $0.339 \pm 0.00$ & $0.418 \pm 0.01$ & $1.27 \pm 0.00$ & $19.29 \pm 0.32$ \\
\hline
\end{tabular}

Values are expressed as mean $\pm \mathrm{SD}, * n=3$.

The values of angle of repose were found to be between $19.08 \pm 0.72$ to $28.97 \pm 0.86$ (IP limits 31-35), the values for compressibility index was between $13.58 \pm 0.92$ to $22.16 \pm 1.20$ (IP limits 16-20) and hausner's ratio was within $1.19 \pm 0.00$ to $1.30 \pm 0.09$ (IP limits 1.19 to 1.25).

Based on results obtained from Table 5, the granules of all the formulations were found to possess good flow properties and were within the compendial limits of Indian Pharmacopoeia.

\subsubsection{Evaluation of cefpodoxime proxetil floating tablets}

Prepared floating tablets were evaluated for hardness, thickness, weight variation, friability and drug content. 
Table 6. Physiochemical evaluations of tablets containing bicarbonate.

\begin{tabular}{cccccc}
\hline $\begin{array}{c}\text { Formulation } \\
\text { code }\end{array}$ & $\begin{array}{c}\text { Hardness } \\
(\mathrm{kg} / \mathrm{cm} 2)^{\mathrm{a}}\end{array}$ & $\begin{array}{c}\text { Thickness } \\
(\mathrm{mm})^{\mathrm{a}}\end{array}$ & $\begin{array}{c}\text { Weight } \\
\text { variation } \\
(\%)^{\mathrm{b}}\end{array}$ & $\begin{array}{c}\text { Friability } \\
(\%)^{\mathrm{c}}\end{array}$ & $\begin{array}{c}\text { Drug } \\
\text { content } \\
(\%)^{\mathrm{c}}\end{array}$ \\
\hline F1 & $6.6 \pm 0.00$ & $5.82 \pm 0.06$ & $0.665 \pm 0.08$ & $0.45 \pm 0.06$ & $97.84 \pm 0.45$ \\
F2 & $7.2 \pm 0.02$ & $6.0 \pm 0.08$ & $0.786 \pm 0.07$ & $0.38 \pm 0.08$ & $95.86 \pm 0.57$ \\
F3 & $7.1 \pm 0.06$ & $6.20 \pm 0.08$ & $0.835 \pm-$ & $0.58 \pm 0.08$ & $97.6 \pm 0.90$ \\
F4 & $6.9 \pm 0.09$ & $6.50 \pm 0.06$ & $0.921 \pm 0.06$ & $0.68 \pm 0.06$ & $96.06 \pm 0.91$ \\
F5 & $6.8 \pm 0.12$ & $5.80 \pm 0.06$ & $1.062 \pm 0.07$ & $0.42 \pm 0.04$ & $98.14 \pm 0.22$ \\
F6 & $7.2 \pm 0.88$ & $5.90 \pm 0.04$ & $0.82 \pm 0.05$ & $0.54 \pm 0.07$ & $97.45 \pm 0.55$ \\
F7 & $7.1 \pm 0.16$ & $5.10 \pm 0.06$ & $0.86 \pm 0.06$ & $0.65 \pm 0.06$ & $96.13 \pm 0.56$ \\
F8 & $7.3 \pm 0.00$ & $5.3 \pm 0.07$ & $0.923 \pm 0.05$ & $0.52 \pm 0.16$ & $97.06 \pm 0.42$ \\
F9 & $7.2 \pm 0.68$ & $5.60 \pm 0.08$ & $0.912 \pm 0.05$ & $0.48 \pm 0.08$ & $97.8 \pm 0.51$ \\
F10 & $7.0 \pm 0.09$ & $5.60 \pm 0.06$ & $1.04 \pm 0.07$ & $0.56 \pm 0.07$ & $96.8 \pm 0.42$ \\
F11 & $6.9 \pm 0.77$ & $5.90 \pm 0.04$ & $0.98 \pm 0.06$ & $0.59 \pm 0.06$ & $98.96 \pm 0.6$ \\
F12 & $7.4 \pm 0.07$ & $6.1 \pm 0.05$ & $0.87 \pm 0.05$ & $0.60 \pm 0.08$ & $97.4 \pm 0.7$ \\
F13 & $6.7 \pm 0.00$ & $6.20 \pm 0.04$ & $0.92 \pm 0.02$ & $0.52 \pm 0.04$ & $96.1 \pm 0.2$ \\
\hline
\end{tabular}

Values are expressed as Mean $\pm \mathrm{SD}, \quad$ a: $n=5$, b: $n=20$, c: $n=10$

The results of hardness, thickness, weight variation, friability and drug content shown in Table 6. The hardness of cefpodoxime proxetil floating tablets was found to be in the range of $5.7-7.4 \mathrm{~kg} / \mathrm{cm}^{2}$. The thickness of the tablets was found to be in the range of 4.80 $-6.50 \mathrm{~mm}$. In weight variation test, the pharmacopoeia limit for the \% deviation for the tablets of above $324 \mathrm{mg}$ (USP) is $\pm 5 \%$. The average \% deviation of all the tablet formulations was found to be within the limits. The percentage friability of all the formulations was below $1 \%$ indicating that the friability was within the prescribed limits. The drug content values varied between $95.86-98.96 \%$. Thus all the parameters of the floating tablets were within compendial standards.

\subsubsection{Buoyancy / Floating test}

From the results given in Table 7, it is evident that sodium bicarbonate has significant effect on lag time. Total floating times were increased and floating lag times decreased with the increase in $\mathrm{NaHCO}_{3}$ concentrations. The minimum lag time was found to be 14 minutes $[10,11]$. 
Table 7. Floating lag time and total floating time of formulations.

\begin{tabular}{ccc}
\hline $\begin{array}{c}\text { Formulation } \\
\text { code }\end{array}$ & $\begin{array}{c}\text { Floating lag time } \\
(\text { min. })\end{array}$ & $\begin{array}{c}\text { Total floating time } \\
\text { (hrs })\end{array}$ \\
\hline F1 & More than 1 hour & $>12$ \\
F2 & More than 1 hour & $>12$ \\
F3 & More than 1 hour & $>12$ \\
F4 & 39 & $>12$ \\
F5 & 36 & $>12$ \\
F6 & 31 & $>12$ \\
F7 & 20 & $>12$ \\
F8 & Integrity of tablet was lost & $>12$ \\
F9 & 25 & $>12$ \\
F10 & 20 & $>12$ \\
F11 & 20 & \\
F12 & 14 & $>12$ \\
\hline
\end{tabular}
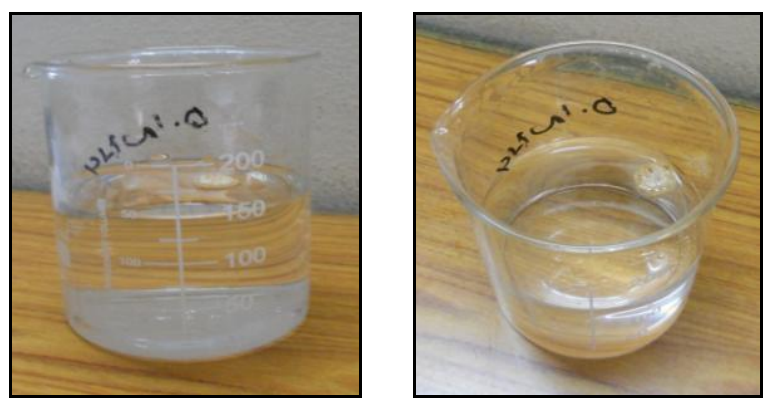

Fig. 2. Floating of cefpodoxime proxetil tablets containing effervescent agent. 
The formulations showing lag time of less than 30 minutes and total floating time of greater 12 hours were selected and subjected to dissolution studies for optimization of floating tablets.

\subsubsection{In vitro drug dissolution testing of floating tablets}

Hence based on results of floating studies, the formulations F7, F8, F10, F11, F12 and F13 were selected and subjected for dissolution studies for further optimization. Fig. 3 shows dissolution profiles.

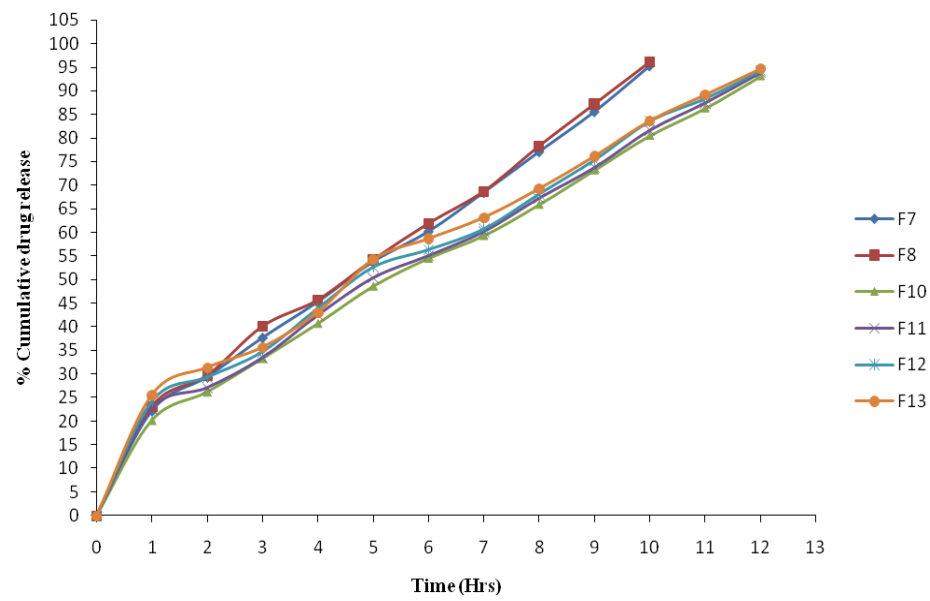

Fig. 3. Dissolution profiles of different formulations.

Formulations F10, F11, F12 and F13 containing locust bean gum and sodium bicarbonate in different ratios have shown sustained release for $12 \mathrm{hrs}$ [12-14]. It was observed that as the concentration of $\mathrm{NaHCO}_{3}$ increases the effervescence or liberation of $\mathrm{CO}_{2}$ increases thereby reduces the floating lag time and increases floating buoyancy due to increased porosity by the gas forming agent.

\subsubsection{In vivo buoyancy study}

In vivo buoyancy was determined by X-ray imaging studies on healthy rabbits. The animal dose was calculated using dose translation based on Body Surface Area (BSA). Fig. 4 depicts the position and nature of the tablets at different time intervals after oral administration.

From the obtained results it was observed that the floating tablets formulated with cefpodoxime proxetil and locust bean gum remained in the gastric region even after 8 hours of administration indicating good retention of the tablets in the stomach region. 


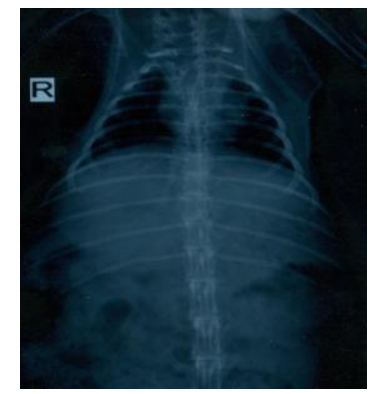

(A) Before administration

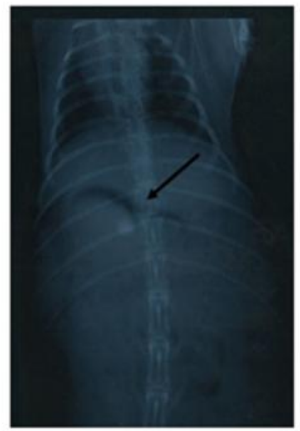

Immediately After Administration

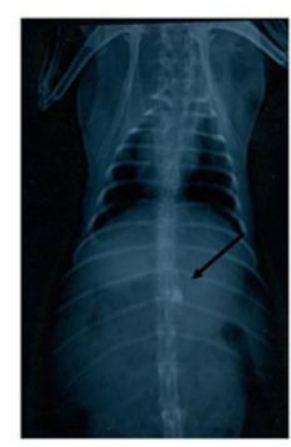

After 1 hr Administration

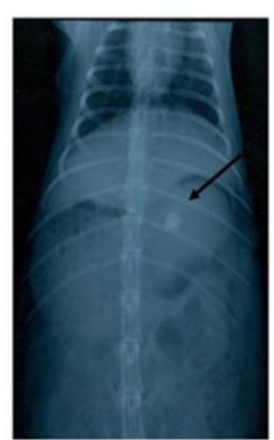

After 2 hrs of Administration

(B) Immediately after administration, After $1 \mathrm{hr}$, After 2 hrs Administration

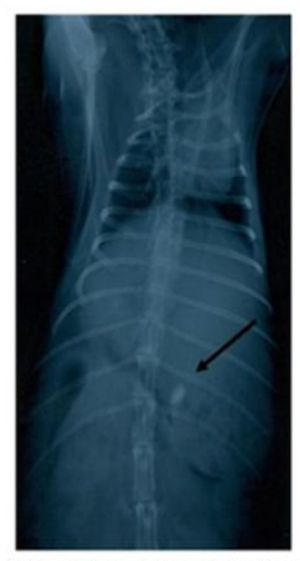

After 4 hrs Administration

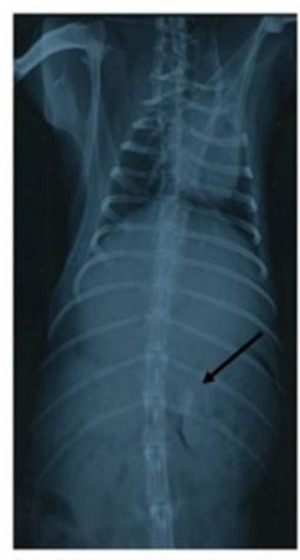

After 6 hrs Administration

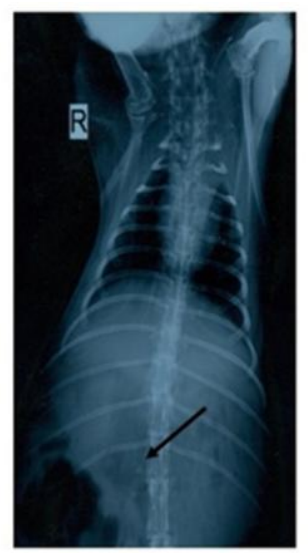

After 8 hrs Administration

(C) After 4 hrs, After 6 hrs and 8 hrs Administration

Fig. 4. X-ray photographs of GIT of rabbit at different time intervals after administration of floating tablet. 


\subsubsection{Drug release kinetic- model dependent method [15-17]}

Release kinetics for different formulations was calculated using Microsoft Office Excel 2007 version. The release data was analyzed by fitting the drug release profiles of all the formulations into zero, first, Higuchi and Korsmeyer-Peppas model. Regression coefficients $\left(\mathrm{R}^{2}\right)$ were calculated for all the formulations.

Table 8. Model dependent kinetic analysis for the dissolution profile of different formulation.

\begin{tabular}{ccccccl}
\hline \multirow{2}{*}{ Formulation } & Zero order & First order & Higuchi & \multicolumn{2}{c}{ Korsmeyer-Peppas } & \multirow{2}{*}{ Release mechanism } \\
& $R^{2}$ & $R^{2}$ & $R^{2}$ & $R^{2}$ & $n$ & \\
\hline F7 & 0.9646 & 0.8512 & 0.9628 & 0.9832 & 0.6247 & Anomalous transport \\
F8 & 0.9823 & 0.8398 & 0.9645 & 0.9796 & 0.6318 & Anomalous transport \\
F10 & 0.9836 & 0.9248 & 0.9714 & 0.9853 & 0.6374 & Anomalous transport \\
F11 & 0.9796 & 0.9177 & 0.9724 & 0.9745 & 0.607 & Anomalous transport \\
F12 & 0.9736 & 0.9207 & 0.9755 & 0.9721 & 0.5788 & Anomalous transport \\
F13 & 0.9846 & 0.9221 & 0.9789 & 0.9889 & 0.5581 & Anomalous transport \\
\hline
\end{tabular}

Based on the results of model dependent kinetic analysis of dissolution profiles of the different formulation i.e. F7 to F13, it was found that the release of the drug from these formulations followed zero order kinetics and mechanism of release was found to be anomalous transport. It was evident from $\mathrm{R}^{2}$ and ' $\mathrm{n}$ ' values, as higher $\mathrm{R}^{2}$ value of 0.9846 indicates zero order drug release and slope of Korsmeyer-Peppas plot is 0.9889 indicates that the formulation followed non-Fickian diffusion kinetics (because $n>0.5$ ) shown in Table 9. Hence from the results F8 was considered as optimized formulation.

\subsubsection{Accelerated stability studies}

Optimized formulation F13 was subjected for stability studies and results are given in Table 9 and Fig. 5.

Table 9. Physico chemical properties of optimized formulation during stability studies.

\begin{tabular}{lllll}
\hline \multirow{2}{*}{ Parameters } & \multicolumn{2}{c}{ Time in weeks } & \\
& 0 (Initial) & 1st week & 2nd Week & 1st month \\
\hline Floating lag time & No lag time & No lag time & No lag time & No lag time \\
Floating time & $>12$ hours & $>12$ hours & $>12$ hours & $>12$ hours \\
Drug content $(\%)$ & $98.3 \pm 0.38$ & $97.6 \pm 0.69$ & $96.5 \pm 1.06$ & $97.5 \pm 0.73$ \\
\hline
\end{tabular}




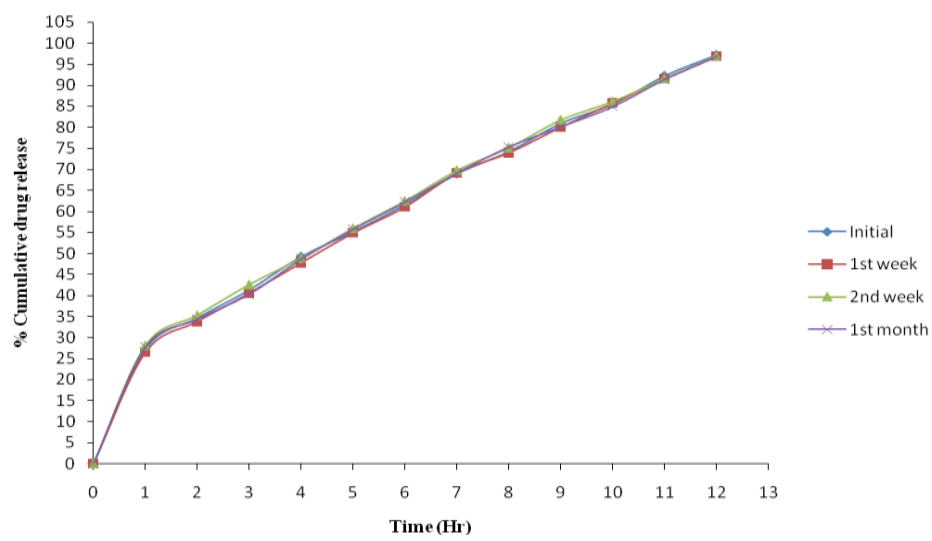

Fig. 5. Percentage drug release of optimized formulation during accelerated stability studies.

Based on the results it can be concluded that, optimized tablets were stable during accelerated stability studies, with insignificant change in the floating lag time, floating time, drug content and in vitro drug release characteristics.

\section{Conclusion}

In conclusion, F13 formulation which has been prepared using locust bean gum as rate control polymer at the ratio of 0.3:1.0 (locust bean gum: drug), shows better floating properties such as <14 min. and 95\% drug release in $12 \mathrm{hrs}$ dissolution as required. Hence, F13 can be concluded as final optimized formulation for floating matrix tablet of cefpodoxime proxetil as an approach to increase gastric residence time and thereby improving its bioavailability.

\section{References}

1. K. V. Kumar, A. V. Kumar, B. A. Kumar, Pharm. Soc. Japan. 128 (3), 439 (2008).

2. M. Chavanpatil, P. Jain, S. Chaudhari, R. Shear, and P. Vavia, Int. J. Pharm. 304,178 (2005). http://dx.doi.org/10.1016/j.ijpharm.2005.08.009

3. P. Laurienzo, Mar Drugs. 8, 2435 (2010). http://dx.doi.org/10.3390/md8092435

4. M. Rinaudo, Polym Int. 57, 397 (2008). http://dx.doi.org/10.1002/pi.2378

5. C. Beneke, A. Viljoen, J. Hamman, Molecules14, 2602 (2009). http://dx.doi.org/10.3390/molecules 14072602

6. Indian Pharmacopeia, vol. II (2010), (Published by Indian Pharmacopeia Comminsion, Ghaziabad, 2010) pp. 751- 754.

7. A. H. Merchant, M. H. Shoaib, T. Jaweria, I. Rabia, and Yousuf, AAPS Pharm. Sci. Tech. 7 (3), 1 (2006). http://dx.doi.org/10.1208/pt070378

8. United States Pharmacopeia 24 and National Formulary 19, 2000 by United States Pharmacopeial Convention, INC, pp. 1941-43.

9. M. S. S. Swamy, A. S. K. Shetty, M. S. A. Kumar, Int. J. Pharm Tech. Res. 4 (2), 750 (2012).

10. S. Neha, J. Nidhi, C. K. Sudhakar, J. Sanjay. Intern. J. Pharmaceut. Res. 4 (2), 82 (2012). 
11. K. S. Rao, R. Rakesh, Vairagkar, B. Dattatreya, Udgirkar, S. Praveen, Patil, V. Karnakumar, and Biradar, J. App. Pharm. Sci. 1 (10), 190 (2010).

12. P. Pramod, B. S. Rao, V. S. Kulkarni, Basavaraj, S. Chetan, and A. Anand, Asian J. Res. Pharm. Sci. 1 (1), 17 (2011).

13. A. Rajamma, H. Yogesha, and S. Sateesha, DARU J. Pharm. Sci. 20, 58 (2012).

14. B. Vineet and K. Sokindra, Int. Pharm. Sciencia 2 (2), 115 (2012).

15. T. Higuchi, J. Pharm. Sci. 52, 1145 (1963). http://dx.doi.org/10.1002/jps.2600521210

16. R. W. Korsmeyer, R. Gurny, E. M. Doelker, P. Buri, and N. A. Peppas, Int. J. Pharm. 15, 25 (1983). http://dx.doi.org/10.1016/0378-5173(83)90064-9

17. N. A. Peppas, Pharm Acta Helv. 60, 110 (1985). 